\title{
INVESTIDORES INSTITUCIONAIS E O FINANCIAMENTO DA INFRAESTRUTURA NO BRASIL: UMA ESTIMATIVA DA OFERTA POTENCIAL DE INVESTIMENTO1,2
}

Katia Rocha ${ }^{3}$

\section{SINOPSE}

Qual o volume de recursos em potencial de investidores institucionais - fundos de pensão, seguradoras, fundos de investimento e fundos soberanos - para financiamento da infraestrutura no Brasil nos próximos dez anos? Institucionais globais (OCDE) e domésticos seriam capazes de financiar totalmente a atual lacuna de infraestrutura no Brasil estimada em mais de $2 \%$ do PIB? Este estudo se propóe a estimar tal figura a partir de estudos similares para as economias emergentes.

Palavras-chave: infraestrutura; investimentos; investidores institucionais.

\section{INTRODUÇÃO}

A infraestrutura inadequada é atualmente uma das principais barreiras ao crescimento e ao desenvolvimento econômico brasileiros. O setor público e o privado, juntos, responderam por menos de $2 \%$ do produto interno bruto (PIB) na média anual de investimentos no setor entre 2008 e 2018. Estimativas do Banco Mundial sugerem que esses investimentos deveriam situar-se ao redor de $4 \%$ do PIB para um crescimento sustentável.

Há certo consenso de que somente o investimento público não é suficiente para aumentar o estoque e a qualidade da infraestrutura brasileira para os níveis adequados. Dada a necessidade considerável de investimento em infraestrutura de longo prazo, o Brasil precisaria melhorar a eficiência do investimento público e, ao mesmo tempo, mobilizar o capital privado em escala e ritmo, tendo que gerar, portanto, as condiçóes para incentivar substancialmente o investimento privado em infraestrutura.

Nesse contexto, a participação dos investidores institucionais, globais e domésticos - fundos de pensão, seguradoras, fundos de investimentos e fundos soberanos -, configura uma importante fonte de recursos de longo prazo para o setor de infraestrutura no Brasil.

O volume dos ativos sob gestão desses investidores superou US\$ 100 trilhóes e apresentou crescimento expressivo com taxa média de 6\% ao ano (a.a.) na última década. Em 2019, investidores institucionais detinham ativos da ordem de US\$ 117 trilhóes no conjunto dos países que compóem a Organização para a Cooperação e Desenvolvimento Econômico (OCDE), e de US\$ 1,81 trilhão no Brasil, conforme ilustra a tabela 1.

1. DOI: http://dx.doi.org/10.38116/radar64art2.

2. As opiniões emitidas nesta publicação são de exclusiva e inteira responsabilidade do(s) autor(es), não exprimindo, necessariamente, o ponto de vista do Ipea.

3. Técnica de planejamento e pesquisa na Diretoria de Estudos e Políticas Setoriais de Inovação e Infraestrutura (Diset) do Ipea. E-mail: <katia.rocha@ipea.gov.br>. 
TABELA 1

Investidores institucionais - ativos totais (2019)

(Em US\$ trilhão)

\begin{tabular}{llr}
\hline & \multicolumn{1}{c}{ Investidor institucional } & Ativo \\
\hline OCDE & Fundos de pensão & 32,27 \\
OCDE & Seguradoras & 29,74 \\
OCDE & Fundos de investimentos & 40,89 \\
OCDE & Fundos de pensão público e de reserva & 6,00 \\
OCDE & Fundos soberanos & 8,30 \\
\hline Brasil & Total & 117,21 \\
Brasil & Fundos de pensão & 0,22 \\
Brasil & Seguradoras & 0,29 \\
& Fundos de investimentos & 1,30 \\
\hline
\end{tabular}

Fontes: OECD Institutional Investors Statistics; OECD Pension Markets in Focus; OCDE Annual Survey of Large Pension Funds and Public Pension Reserve Funds; OECD Insurance Statistics; Sovereign Wealth Fund Institute; Anuário da Indústria de Fundos de 2020, do Centro de Estudos em Finanças da Fundação Getulio Vargas (FGVcef).

O setor de infraestrutura possui muitas características desejáveis aos investidores institucionais. A sua baixa correlação com ativos tradicionais gera oportunidades de diversificação. A estabilidade temporal dos fluxos de caixa pode fornecer hedge e funding à longa duração do passivo dos fundos de pensão ou seguradoras de vida. Retornos justos e atrativos a longo prazo provenientes de receitas de tarifas fornecem proteçáo contra a inflaçáo e os ciclos econômicos.

A participação desses investidores no setor aumentou gradualmente após a crise financeira global de 2008. A presença do capital privado na classe de ativos de fundos de infraestrutura passou de US\$129 bilhóes em 2009 para cerca de US $\$ 582$ bilhóes em 2019, um crescimento médio de cerca US\$ 50 bilhóes por ano, com projeçóes de atingir a marca de US\$ 1 trilhão ao final de 2023. A alocação atual situa-se ao redor de $2 \%$ da carteira total de ativos sob gestão e espera-se um aumento gradual da ordem de $2 \%$ a $3 \%$ na proxima década.

Diante disso, este artigo pretende estimar o volume de recursos em potencial de investidores institucionais (globais e domésticos) para financiamento da infraestrutura no Brasil nos próximos dez anos.

\section{METODOLOGIA E RESULTADOS}

Investidores institucionais não são homogêneos e possuem ampla gama de objetivos, abordagens de investimento e fatores estruturais que influenciam seu investimento, além de restriçóes regulatórias.

As variáveis-chave utilizadas neste estudo para a estimação do volume de recursos em potencial para a infraestrutura brasileira são: i) estimação dos ativos sob gestão dos investidores institucionais, considerando-se restriçóes estruturais de liquidez, tamanho e perfil; ii) expectativa de aumento de $2 \%$ a $3 \%$ na alocaçáo do segmento de infraestrutura na carteira de ativos desses institucionais nos próximos dez anos; iii) dinâmica de crescimento dos ativos dos investidores institucionais que cresceram cerca de $6 \%$ a.a. na última década; e iv) estimativa do market share do Brasil no volume potencial de recursos globais para infraestrutura da ordem de 2,5\% a 3,5\%.

A estimativa de recursos em potencial de investidores institucionais globais e domésticos para a infraestrutura no Brasil situa-se entre US\$ 9 e US\$ 17 bilhóes anuais nos próximos dez anos, equivalentes a $0,5 \%-1 \%$ do PIB de 2019 por ano. No melhor cenário, mantendo-se os níveis atuais de investimento de cerca de 2\% do PIB, o fluxo potencial de investidores institucionais elevaria o nível para cerca de 3\% do PIB, valor considerável, porém ainda aquém da meta recomendada pelo Banco Mundial de $4 \%$ por ano. 


\section{CONCLUSÕES}

A participação de investidores institucionais globais e domésticos no financiamento da infraestrutura no Brasil apresenta potencial de financiamento anual da ordem de 0,5\%-1\% do PIB nos próximos dez anos. Embora considerável, tal estimativa seria insuficiente para se fechar a lacuna de infraestrutura existente de mais de $2 \%$ do PIB a.a. Os resultados encontrados estáo em linha com as estimaçóes de trabalhos correlatos para outros emergentes, o que demonstra certa robustez. Ressaltamos que essa estimativa não é projetada para produzir uma figura exata, mas, sim, uma indicação da escala do recurso potencial dos investidores institucionais na classe de ativos de infraestrutura no Brasil, dadas as hipóteses e restriçóes, as mais realistas possíveis, e de acordo com a literatura específica.

\section{REFERÊNCIAS}

INDERST, G.; STEWART, F. Institutional investment in infrastructure in emerging markets and developing economies. Washington: World Bank, 2014.

ROCHA, K. Investidores institucionais e o financiamento da infraestrutura no Brasil: uma estimativa da oferta potencial de investimento. Rio de Janeiro: Ipea, ago. 2020 (Texto para discussão, n. 2584). 